Working Paper 11-40

Economic Series (48)

May 2013
Departamento de Economía

Universidad Carlos III de Madrid

Calle Madrid, 126

28903 Getafe (Spain)

Fax (34) 916249875

\title{
The joint effect of ethnicity and gender on occupational segregation. An approach based on the Mutual Information Index ${ }^{\S}$
}

\author{
Daniel Guinea-Martín, Ricardo Mora, and Javier Ruiz-Castillo ${ }^{1}$
}

\begin{abstract}
This article studies the effects of gender and ethnicity on occupational segregation. The traditional approach to this topic measures the two sources of segregation separately. In contrast, we measure the joint effect of gender and ethnicity by applying a multigroup segregation index-the Mutual Information or $M$ index-to the product of the two genders and seven ethnic groups distinguished in our census data for England and Wales in 2001. We exploit $M$ 's strong group decomposability property to consistently pose the following two questions: (i) How much does each source contribute to occupational segregation, controlling for the effect of the other? (ii) Is the combined impact of gender and ethnicity greater than, equal to, or smaller than the sum of their individual effects? The main empirical findings are the following two. First, we confirm previous results showing the greater importance of gender over ethnicity as a source of occupational segregation. However, we find that ethnicity contributes 13.5 percent of overall segregation in geographical areas where minorities concentrate. Second, contrary to intersectionality theories, we find that there is a small, "dwindling" interaction effect between the two sources of segregation: ethnicity slightly weakens the segregative power of gender, and vice versa.
\end{abstract}

Keywords: Britain, disadvantage, ethnicity, gender, intersectionality, Mutual Information Index, occupations, segregation

$\S$ This is an updated version of the December 2011 Working Paper with the same series number and entitled "Occupational Segregation by Gender and Ethnic Group in Great Britain's Labor Market".

1 Daniel Guinea-Martin (corresponding author), Universidad Nacional de Educación a Distancia (UNED), Calle Obispo Trejo s/n, Madrid 28040, Spain. daniel.guinea@poli.uned.es. Ricardo Mora, Universidad Carlos III Madrid, Spain. Javier Ruiz-Castillo, Universidad Carlos III, Madrid, Spain. Guinea-Martin acknowledges funding from the Economic and Social Research Council of the United Kingdom through grant RES-163-27-1003, and from the Spanish government through contract RYC-2008-03758, and grants CSO2008-03222 and CSO2011-30179-C02-02. Mora acknowledges financial help from the Spanish government through grant ECO2009-11165. Ruiz-Castillo acknowledges financial help from the Spanish government through grant SEJ2007-67436. We thank the Health \& Care and Census divisions of the Office for National Statistics (ONS) at Tichfield for producing the specially commissioned tables of the 2001 England and Wales Census data and, especially, Kevin Lynch for his kind assistance in the process. 
Since the 1970s, feminist researchers have widened the scope of their interest in gender to encompass a variety of sources of inequality. The seminal works of Beal (1969) and Epstein (1973) introduced the idea that ethnicity and gender combine as sources of disadvantage for ethnic minority women. In this article we study occupational segregation, one feature of the labor market that many authors claim contributes to disadvantages for women and minorities (see, for example, Blau, Brinton, and Grusky 2006, and Kaufman 2010). All writers on this topic have concluded that gender is a greater source of occupational segregation than ethnicity (see, inter alia, Albelda 1986; Blackwell 2003; King 1995; Mintz and Krymkowski 2011; Reskin and Cassirer 1996; Tomaskovic-Devey 1993; Wright and Ellis 2000). However, one of the tenets of the so-called "theories of intersectionality," the idea that these two exemplars of ascribed status intertwine in producing inequality (Browne and Misra 2003; King 1988; McCall 2001), has received much less attention in applied research. We translate this interest to the study of occupations by asking the following question: do the segregative effects of ethnicity and gender interact in the ways proposed by intersectional theories? More generally, given the scenarios discussed in the literature we ask whether the combined impact of ethnicity and gender on segregation is greater than, equal to, or smaller than the sum of their individual effects.

The traditional approach to the effects of gender and ethnicity on occupational segregation separately measures segregation by gender, on the one hand, and segregation by ethnic group, on the other. We claim, in contrast, that the problem requires that segregation by gender and ethnic group be jointly, or simultaneously, addressed. We will show how, in this more general framework, it is possible to accomplish the two tasks at hand: (i) the analysis of each source of segregation separately, controlling for the effect of the other source of segregation, and (ii) the study of the different ways in which the two sources may interact. As we have at least two ethnic groups and two genders, for a total of four or more categories, we require a multigroup segregation index that overcomes the limitations of traditional dichotomous indicators such as the well-known Dissimilarity Index originally proposed by Duncan and Duncan (1955).

Moreover, as we must isolate the two sources of segregation from each other, it is essential that the segregation index be additively decomposable for any partition of the population into sub-groups. Fortunately, the Mutual Information Index, $M$, is a multigroup segregation index that satisfies the Strong Group Decomposability property (SGD hereafter). Indeed, Frankel and Volij (2011) have recently shown that the $M$ index is the 
only segregation index that satisfies various acceptable ordinal properties and, in addition, is strongly group decomposable. Therefore, we can only conduct our analysis using the $M$ index.

To exemplify the usefulness of our approach, we draw on the 2001 Census of England and Wales, countries that are among the most ethnically heterogeneous in Europe. ${ }^{1}$ Additionally, we check the sensitivity of our results to two compositional effects that could be driving them. First, a critic could note that the fact that women represent a greater share of the labor force than ethnic minorities biases our measurement. Likewise, some authors argue that the outcomes of ethnic minorities in the labor market are associated with their relative weight in the population (see, for example, Clark and Drinkwater 2002; Catanzarite 2003; Durlauf 2004; Jacobs and Blair-Loy 1996; Tienda and Lii 1987). Therefore, we explore the sensitivity of our results to the ethnic composition of Local Authority Districts, the smallest geographical area for which information on ethnicity is available in standard Census output.

Second, it is reasonable to think that at least some of the segregation that we attribute to ethnicity and gender is really due to differences in the stock of education and potential work experience accrued by women, men, and ethnic groups (for a similar concern, see, among others, Carmichael and Woods 2000; Clark and Drinkwater 2007; Jacobs and Blair-Loy 1996; Reskin and Cassirer 1996). To address this objection, we control for differences in the age profile and educational attainment of the working population.

The remainder of this paper is organized into four sections. In the first section, we briefly review the literature on gender, ethnicity, and occupational segregation. We discuss the traditional approach to the study of gender and ethnic occupational segregation. We then present three scenarios of interaction between gender and ethnicity, where both sources of segregation play roles. Next, we introduce our empirical strategy based on the $M$ index, and afterwards, provide an illustration with British data. ${ }^{2}$ Finally, in the last

\footnotetext{
${ }^{1}$ UK Census data is Crown Copyright. We use the term "gender" throughout the article, rather than "sex" because the occupational segregation of women and men is a macro result of the social construction of gender - a process that is entrenched in institutions such as the labor market (West and Zimmerman 1987). Furthermore, we use the term "ethnicity" in lieu of "race" for two reasons. First, in the Census the respondent is asked about the ethnicity with which she identifies. Second, we reflect the widespread usage of the term "ethnicity" in British English, where "race" is viewed as potentially linked with "essentially racists theories" (Bradley and Healy 2008). When we quote other authors we respect the terms they use. Finally, for brevity we use feminine pronouns as shorthand for both women and men.

${ }^{2}$ Following the usual convention, we use the term Great Britain as shorthand for England and Wales, and British for English and Welsh. Scotland's 2001 Census is an independent statistical operation
} 
section, we summarize our argument.

\section{Traditional Notions: Ethnic Segregation and Gender Segregation}

By segregation we refer to the tendency of members of different groupings (women and men; white and ethnic minority individuals) to be distributed unevenly across organizational units. This is the so-called "evenness" dimension of segregation (Massey and Denton 1988; Reardon and Firebaugh 2002). When the organizational units are workers' occupations, most authors focus exclusively on the notion of occupational segregation by gender for two reasons, one methodological and the other substantive. Methodologically, sociological analyses have been constrained by dichotomous indexes. In the study of women and men, the Dissimilarity Index (DI hereafter), the Gini, and the Karmel-MacLachlan indexes, are natural alternatives (see Flückiger and Silber 1999 for a review). ${ }^{3}$ However, such indexes are not ideal tools when there are more than two groups, as is often the case in ethnic studies. The reason is that, for instance, Asian people are not only more or less segregated from, say, Black people but also from all other ethnic groups (for a similar concern, see, among others, Alonso-Villar, Del Rio, and Gradin 2012).

Nevertheless, the main reason for privileging gender over ethnicity in the study of segregation is substantive: in modern society, gender is "the most basic divide" (Epstein 2007) along which inequality arises. Gender-based differences draw their legitimacy from essentialist beliefs and stereotypes, such as the idea that women are biologically better equipped for caring, nurturing, and servicing tasks than men (Ridgeway 2006). In contrast, the application of essentialist beliefs to ethnic distinctions is taboo, at least in Western societies. Except for overtly racist and marginal groups, the opinion that certain ethnicities are better suited for performing some tasks is not normatively accepted (Jacobs and Blair-Loy 1996). Still, ethnic prejudices appear to influence recruitment, job allocation, and promotion (Carmichael and Woods 2000; Castilla 2008; Catanzarite 2003; Moss

conducted by the General Register Office for Scotland, a part of the devolved Scottish Administration, and we do not use these data in this article.

${ }^{3}$ There are gender categories other than women and men, as gender studies and queer theory evidence. Notwithstanding, these alternative gender groups are not recorded in the British census. 
and Tilly 2001; Reskin, McBrier, and Kmec 1999) through a variety of forms that range from employers' explicit (Becker 1971) or implicit (Bertrand, Chugh, and Mullainathan 2005) preferences for one ethnic group over another to statistical discrimination (Phelps 1972). However, in the aggregate, there are differences in ethnic and gender stereotyping and in the population weight of women and minorities. Many occupations employ women or men almost exclusively (e.g., nurses, drivers). But very few occupations, if any, are dominated by a single ethnic minority (Cohn 1999; Jacobs and Blair-Loy 1996). In short, in spite of the rise of gender egalitarianism since the 1960s, gender essentialism, as Charles and Grusky (2004) calls it, reigns supreme.

If this is the case, then why worry about ethnicity at all when studying occupational segregation? Because the few studies that consider the ethnic affiliations of workers conclude that it shapes their occupational distribution to a noticeable degree (for two recent contributions in this vein, see Åslund and Skans 2010, and Kaufman 2010). In the case of Great Britain, the very ethnic makeup of the country is closely related to the recent evolution of the British labor market. At the end of the Second World War, significant numbers of overseas workers joined British industry and the public sector. For example, the nascent National Health Service recruited sizable numbers of Black and Asian women (Batnitzky and McDowell 2011), while England's textile, clothing and steel industries attracted migrants from the Caribbean and South Asia (Cross 1992; Owen and Green 1992; Phizacklea and Wolkowitz 1995). Some of these original migrants still worked in those occupations at the time of the 2001 Census. In addition, many of their offspring who grew up in Great Britain were already in the labor market at that date (Clark and Drinkwater 2007). Certainly, the labor supply of migrants' descendants is not necessarily tied to the occupational niches in which their forebears found work-particularly if these niches were not very attractive or advantageous (Waldinger and Feliciano 2004) or were in economic sectors that have declined over the years (Allen and Massey 1988; Cross 1992; Crouch 1999). Nevertheless, many observers have concluded that there are substantial differences in economic performance between people with immigrant origins and the rest of the labor force (Berthoud 2000; Clark and Drinkwater 2007; Fernández 2010; Heath and $\mathrm{Yu}$ 2005). For example, ethnic minority entrepreneurs concentrate in the retail, catering, and transport sectors (Parker 2004) but are underrepresented in professional and intermediate non-manual occupations (Carmichael and Woods 2000).

Some authors have, in a single study, examined occupational segregation by gender, 
on the one hand, and occupational segregation by ethnic group, on the other (Abbott and Tyler 1995; Albelda 1986; Alonso-Villar, Del Rio, and Gradin 2012; Author1 and et.al. 2005; Blackwell 2003; Jacobs 1989; King 1995, 2009; Mintz and Krymkowski 2011; Reskin and Padavic 1999; Tomaskovic-Devey 1993; Wright and Ellis 2000). These studies measure the effects of one source of segregation on people's distribution across occupations, and only afterwards do they gauge the effects of the other dimension. If they use dichotomous indices such as the $D I$ or the Gini index, analysts restrict the ethnic contrasts to pairwise comparisons between (i) Whites and the most prominent minority group, which is usually Black people in the US (Cohn 1999; King 1995, 2009; Tomaskovic-Devey 1993); (ii) White people and non-white people (Albelda 1986; Xu and Leffler 1992); (iii) White people and each ethnic minority separately (Hegewisch, Liepmann, Hayes, and Hartmann 2010); or, finally, (iv) between all ethnic-gender pairs that can be formed (Reskin and Cassirer 1996; Wright and Ellis 2000). Studies conducted using the traditional notions of segregation have unanimously concluded that the level of occupational segregation is larger by gender than by ethnicity. They also tell us, for example, that White people are more segregated by gender than Chinese people in Great Britain (Blackwell 2003) or that there is more ethnic segregation among men than among women (see, inter alia, Alonso-Villar, Del Rio, and Gradin 2012).

However, under the widespread procedure of using dichotomous indexes to calculate gender segregation for each ethnic group, and ethnic segregation for each gender, there is no methodologically sound way of integrating these separate indexes to produce meaningful measurements of gender segregation, controlling for ethnicity, and of ethnic segregation, controlling for gender. Moreover, we are unaware of any measurement of the impact on segregation of both statuses together, enabling a comparison of their relative importance directly and unambiguously. We address the substantive nature of this problem in the next section, where we describe three alternative scenarios for the joint effect of ethnicity and gender on segregation. 


\section{The Joint Effect of Ethnic and Gender on Segregation}

In ethnically heterogeneous societies, both ethnicity and gender are arguably part and parcel of our collection of "master statuses" (Becker 1963; Hughes 1945): ${ }^{4}$ the categories to which we are ascribed by virtue of our genitals, skin color, language and cultural heritage (Jacobs and Blair-Loy 1996). To a large extent these are circumstances outside individuals' control. Nevertheless, upon visual and auditive perception of these features, everyone is classified almost immediately as adept or inept in certain tasks and as free of, or subject to, certain norms, duties and expectations. Everyone-including, certainly, employers and employees - knows this, if only unwittingly (Chugh 2004). People carry a wealth of social knowledge triggered by the physical cues of their phenotype.

We all belong to one gender and one ethnic group at the same time (Reskin 1993) and are easily perceived as members of these groups in the labor market. ${ }^{5}$ Hence, the traditional approach, which appraises each dimension separately, makes sense only if workers' ascribed characteristics have an additive relationship. Ethnicity puts minority women at a disadvantage. Simultaneously, but independent of ethnic discrimination, these women also suffer the consequences of sexism. Abbott and Tyler (1995) and Blackwell (2003) find evidence of this segregation pattern in Britain.

Few authors, however, argue on theoretical grounds in favor of the additivity of the effect of ethnicity and gender. In particular, social scientists advocating an intersectional perspective (see, inter alia, Bradley and Healy 2008; Misra 2012) aim to prove that ethnicity and gender "are not independent analytic categories that can simply be added together" and "have separate (...) influences" (Browne and Misra 2003). Instead, they seek "evidence to demonstrate that race and gender intersect in the labor market." This second scenario corresponds to what King (1988) calls the "multiple jeopardy hypothesis": the general outcome of being oppressed on various accounts exceeds the sum of the outcomes of being disadvantaged on each dimension separately. With regard to occupational segregation, the evidence most often offered in favor of the intersection of ethnicity and

\footnotetext{
${ }^{4}$ It could be argued that this set also includes the major age groups that we successively occupy during the life cycle: childhood, teenage years, young adulthood, adulthood, seniority (Collins 2000). This is another argument for checking the robustness of our results with a proxy for work experience that includes age among its component parts, as we argue later in the article.

${ }^{5}$ This is also the case of people who could, in principle, claim many ethnic identities. For example, in the British Census contains various mixed options that we do not consider in this article for reasons discussed in the Data section.
} 
gender is the crowding of ethnic minority women into the most menial, least desirable activities, while white women perform skilled and administrative tasks (Nakano Glenn 1985; King 1995; Phizacklea and Wolkowitz 1995).

Surprisingly, most contributions to the debate on the compound effect of ethnicity and gender are based on qualitative evidence or on qualitative interpretations of crosstabulations of ethnicity, gender and broad occupational titles (see, for example, Abbott and Tyler 1995; King 1995) and sets of pairwise indexes (Blackwell 2003; King 1995). To our knowledge, only Reskin and Cassirer (1996) and Wright and Ellis (2000) explicitly debate the question in statistical terms.

If both forms of ascribed status are the source of at least some non-negligible segregation in the workplace and if they interact in the sense proposed in the intersectional tradition, then when we separately estimate one of the two types, e.g., the segregative effect of people's gender status, as if they had no ethnic ascription, we report a potentially inflated measure of gender segregation. The quantity that we obtain includes the part of segregation that arises from the interaction between gender and ethnicity through, for example, racialized and gendered job queues (Lieberson and Waters 1988; Reskin and Roos 1990). Consequently, the resulting index will overestimate the contribution that being a woman or a man has on people's occupational distribution (see Reskin and Cassirer 1996, p. 241 on the same idea).

Apart from their contribution to the previous point, Reskin and Cassirer (1996) note that "the social processes that produce sex segregation typically relegate women and men to different occupations, thereby preempting or at least minimizing the segregative effect of race" (ibid.: 237). In other words, gender and ethnicity interact, but not in the way envisaged by intersectional theorists: rather than multiplying their repercussions, gender, the status that by itself seems to segregate workers the most, softens the impact of ethnicity - which, to begin with, is a lesser dimension in terms of its segregation potential. More generally, we propose a third scenario in which each of the two ascribed characteristics concentrates workers in a sub-set of occupations, and the effect of the second characteristic is curtailed to some extent. This final possibility reflects an interaction that diminishes the effect on segregation of each status. We refer to it, in short, as the "dwindling interaction" between ethnicity and gender. In this third scenario, the traditional measurements of gender segregation underestimate the net contributions of both gender and ethnic status to the segregative process. 


\section{An Approach Based on the Mutual Information Index}

The starting point of our empirical strategy is simple. People belong to one of two genders and, in our data, one of seven ethnic groups: White, Indian, Pakistani, Bangladeshi, Black Caribbean, Black African, and Chinese (see Data section). Hence, the segregation that we measure stems from the uneven distribution of $2 x 7=14$ groupings across occupations. To avoid the need to constantly repeat "ethnic and gender," we also refer to this notion as "total" or "overall" segregation. To conduct an analysis that combines ethnic and gender categories, we must employ a multigroup index of segregation.

We must also employ an index of segregation that satisfies the property of Strong Group Decomposability (SGD) defined by Frankel and Volij (2011). The reasons are twofold. First, an index that satisfies $S G D$ allows us to identify the proportion of occupational segregation by ethnicity and gender that can be attributed exclusively to either ethnicity or gender (Author2 and Author3 2011). Second, once we can compute the proportion of segregation attributable to each source, controlling for the other, we can study whether the sum of these two quantities is greater than, equal to, or smaller than total segregation. In the first case, gender and ethnicity interact in a multiplicative way; in the second case, they do not interact; and in the third case, they interact in a dwindling way.

As indicated in the Introduction, Frankel and Volij (2011) have shown that the $M$ index is the only segregation index that, in addition to possessing other desirable properties, satisfies the $S G D$ property. ${ }^{6}$ Therefore, the remainder of this Section is devoted to a brief presentation of the $M$ index and its properties relevant to this study. However, before we do so, we must define the entropy of a distribution (see Hamming 1991 for an overview).

Consider a variable $X$ which takes a value $q$ with probability $p_{q}$. In Information Theory, $\log \left(\frac{1}{p_{q}}\right)$ captures the amount of information, or "surprise," experienced when we observe $q$ : if $q$ is unlikely, then $p_{q}$ is small; consequently, the information that $q$ carries, defined as $\log \left(\frac{1}{p_{q}}\right)$, is large. To illustrate, consider the distribution of British workers by ethnicity (see the last column of Table 1 below). An overwhelming 94.5

\footnotetext{
${ }^{6}$ One normalized version of the $M$ index, known as Theil's $H$ index, satisfies a weaker decomposability property than SGD (Frankel and Volij 2011; Reardon and Firebaugh 2002). However, Author2 and Author3 (2011) have demonstrated the shortcomings of the $H$ index and the weaker decomposability property that it satisfies.
} 
percent of this population is White. Therefore, if we sampled one person in the working population and she happened to be White, we would not be very surprised. In more technical terms, the information gained would be small: $\log \left(\frac{1}{0.945}\right)=0.06$, to be precise. If we sampled an Indian person, a less likely event, the amount of information obtained is $\log \left(\frac{1}{0.021}\right)=3.86$, or $\frac{3.86}{0.06}=64$ times larger than in the case of a white person. The entropy of the distribution of $p_{q}$ is the expected value of the information attained with the variable $X: E(P)=\sum p_{q} \log \left(\frac{1}{p_{q}}\right)$, where $P=\left\{p_{q}\right\}$ denotes the probability distribution of $X$. In our example, $E(P)=0.30$.

Let $P_{o c c}$ and $P_{o c c \mid e, g}$ be the unconditional and conditional distribution of occupations, respectively. Suppose we sample a worker randomly. The entropy of $P_{\text {occ }}, E\left(P_{\text {occ }}\right)$, is defined as the expected information obtained from learning the worker's occupation. If we were also informed about the worker's ethnicity and gender, the expected information from learning the worker's occupation would now be measured by the entropy of the distribution conditional on ethnicity and gender, $E\left(P_{o c c \mid e, g}\right)$. The $M$ index of total or overall segregation, denoted by $M^{*}$, is the average increase in the information we have about the worker's occupation that comes from learning her or his ethnicity and gender:

$$
M^{*}=\sum_{e, g} w_{e, g}\left[E\left(P_{o c c}\right)-E\left(P_{o c c \mid e, g}\right)\right]
$$

where $w_{e, g}$ is the demographic weight of workers of ethnic group $e$ and gender $g$. If all groups are equally distributed across occupations, then $M^{*}$ attains its minimum at 0 . Conversely, $M^{*}$ reaches its maximum if groups do not mix together in occupations and all groups have identical demographic weights. This quantity is equal to the smaller value of either the logarithm of the number of groups or the logarithm of the number of occupations. ${ }^{7}$

\section{A crucial property: Strong Group Decomposability}

The $S G D$ property states that for any partition of the population into subgroups, $M^{*}$ equals the sum of the segregation between subgroups and a weighted average of withinsubgroup segregation levels, where the weights are the population shares of each subgroup. We can study the segregation induced by a given source, e.g., gender, in two ways. In

\footnotetext{
${ }^{7}$ See Frankel and Volij (2011) for a motivating example of this requirement.
} 
the first case we have the "between-term" denoted by $M^{g}$, which is called thus because it gauges the segregation that arises from distinguishing between women and men in the overall population. This term is equivalent to traditional measurements of gender segregation.

In the second case, the $M$ index of gender segregation within an ethnic group $e, M^{g}(e)$, captures the average increase in information that arises from learning the worker's gender, given that the ethnicity is $e$, with $e=1, \ldots, E$. The weighted average of these indexes, $\sum_{e} p_{e} M^{g}(e)$, is the "within-term" in the decomposition of $M^{*}$, which is called thus because it measures the central tendency of gender segregation within an ethnic group. Similarly, we can study segregation between ethnic groups in the population, $M^{e}$, and also within gender groups, $M^{e}(g)$. The corresponding within-term is $\sum_{g} p_{g} M^{e}(g)$.

As the $M$ index fulfills the $S G D$ property, the overall index $M^{*}$ defined in equation (1) satisfies the following two decompositions: ${ }^{8}$

$$
M^{*}=M^{g}+\sum_{g} p_{g} M^{e}(g)=M^{e}+\sum_{e} p_{e} M^{g}(e) .
$$

The first equality in equation (2) states that $M^{*}$ can be decomposed into segregation by gender, $M^{g}$, and ethnicity's contribution to segregation after controlling for gender, $\sum_{g} p_{g} M^{e}(g)$. Alternatively, $M^{*}$ can be decomposed into occupational segregation by ethnic group, $M^{e}$, and the effect that gender has on segregation once ethnicity is controlled for, $\sum_{e} p_{e} M^{g}(e)$.

Equation (2) is important because it quantifies how much of ethnic and gender segregation is exclusively due to either ethnicity or gender. More precisely, the within-terms answer the following question: how much of the overall segregation would disappear if gender (in the case of $\sum_{e} p_{e} M^{g}(e)$ ) or ethnicity (in the case of $\sum_{g} p_{g} M^{e}(g)$ ) played no role in the segregative process? Hence, each within-term singles out the contribution to overall segregation that can be attributed to one dimension on its own, once we control for the other (Author2 and Author3 2011). As these contributions do not contain the segregation that arises from the interaction between ethnicity and gender, the withinterms can be considered the "marginal" effects of either ethnicity or gender on overall segregation. ${ }^{9}$

\footnotetext{
${ }^{8}$ See Author2 and Author3 (2011) for the proof of this result in the case with only two groups and Frankel and Volij (2011) for the multigroup case.

${ }^{9}$ See also Puyenbroeck, Bruyne, and Sels 2012 for an alternative decomposition in the analysis of the
} 


\section{The three scenarios for the joint effect of ethnicity and gender and a single analytical framework}

The decomposition in equation (2) is ancillary to the identification of the interaction between ethnicity and gender. It provides a single analytical framework for evaluating which of the three scenarios concerning the joint effect of ethnicity and gender holds true in a given time and place. Simple arithmetical manipulation of equation (2) identifies the putative intersection of ethnicity and gender, denoted by $I$, as follows:

$$
I=M^{*}-\left(\sum_{g} p_{g} M^{e}(g)+\sum_{e} p_{e} M^{g}(e)\right)
$$

Alternatively, we can interpret $I$ as the portion of the segregation jointly induced by ethnicity and gender that cannot be attributed uniquely to either of these two factorsand that, consequently, arises from their interaction:

$$
I=M^{e}-\sum_{g} p_{g} M^{e}(g)=M^{g}-\sum_{e} p_{e} M^{g}(e) .
$$

The value of $I$ in equations (3) or (4) indicates which of the three scenarios pertains in a given instance. When $I=0$, the sum of the exclusive contributions of ethnicity and gender to segregation, $\sum_{g} p_{g} M^{e}(g)$ and $\sum_{e} p_{e} M^{g}(e)$, add up to their joint effect, $M^{*}$. In this case, such contributions are equal to the traditional measures of ethnic segregation, $M^{e}$, and gender segregation, $M^{g}$. This is the additive scenario, in which ethnicity and gender do not interact in producing segregation.

When $I>0$, there is a part of $M^{*}$ that cannot be attributed to either factor in isolation. This part results from the interaction of gender and ethnicity in the multiplicative scenario. In this case, traditional measures overestimate the amount of segregation induced by each status: $M^{e}>\sum_{g} p_{g} M^{e}(g)$ and $M^{g}>\sum_{e} p_{e} M^{g}(e)$.

When $I<0$, ethnicity and gender interact in the sense that their combination produces less segregation than we would observe if we simply added together the net segregative effects of each status. Through their joint effect, the marginal contributions of ethnicity and gender taper off. This is the dwindling scenario, in which traditional measures underestimate the portion of segregation that each status begets: $M^{e}<\sum_{g} p_{g} M^{e}(g)$

interaction of education levels and occupations in gender segregation. 
and $M^{g}<\sum_{e} p_{e} M^{g}(e)$.

\section{Robustness checks}

To this point, we have argued that traditional indexes measure the strength of the association between one variable, normally gender or ethnicity, and occupation. As an alternative, we have proposed an approach in which a multigroup index of segregation jointly applies to both dimensions. We now wish to consider two possible objections to our research design. These objections concern the so-called "compositional effects."

In the first place, we know that minorities are not distributed evenly and randomly across a given geographical area (Jacobs and Blair-Loy 1996). In Great Britain, for example, they cluster in certain areas, mostly urban, as a result of labor demands at certain points in history (Clark and Drinkwater 2002; Cross 1992). To assess the sensitivity of our results to the percentage of the population that belongs to a minority, we have created two "sub-countries" in our data. One is composed of the geographical areas in which minorities concentrate. In the other areas, minorities represent only a negligible proportion of the overall population. (We present the details in the Data section.) If our measures are robust to the ethnic composition of the areas, the amount of ethnic segregation, its joint effect with gender, and the intersection of ethnicity and gender, should be roughly equal, independently of the ethnic mix of the area.

Second, we should bear in mind that economists' main supply-side explanation of differences between women and men in occupational outcomes relies on the notion of human capital, i.e., the acquired stock of competences to work and produce economic value. The nub of the theory is that people accrue education and work experience as a result of investment decisions that affect their future earnings and occupations (BenPorath, 1967). Consequently, observed occupational segregation must be associated, at least partly, with group differences in levels of human capital. Hence, as a robustness check on our findings, we evaluate to what extent ethnic and gender differences in human capital characteristics account for occupational segregation. How do we expect segregation levels and the intersection of ethnicity and gender to vary, once we control for the human capital characteristics of the working population? From the literature, we can think of two possible outcomes. The first responds to the meritocratic ideal and the second to the specialization of population subgroups in certain types of occupations. We 
review each in turn.

One of the main findings regarding the link between human capital and gender segregation indicates that many women with college degrees and continuous work histories are employed in male and integrated occupations, thereby decreasing the overall level of segregation (Cotter, Hermsen, and Vanneman 2004; Hakim 2004). In the case of ethnicity, the role of human capital is less clear-cut because it depends, to some extent, on where it was acquired. Customarily, employers in migrants' countries of destination either do not recognize or somewhat devalue the education achieved in migrants' countries of origin, particularly if the language is different (Heath and Yu 2005; Platt 2005). However, for ethnic minority people who earned their educational credentials in the country where they work, the consequences of human capital should be similar, in principle, to the outcomes observed among women and men: the higher the education level achieved, the greater the potential for making inroads into jobs with meritocratic points of entry. In summary, if achieved status and merit buffer some of the discrimination brought about by ascribed status (Carmichael and Woods 2000; Mintz and Krymkowski 2011; Reskin, McBrier, and Kmec 1999), we should observe that segregation jointly induced by ethnicity and gender, as well as any multiplicative interaction between these two dimensions, diminishes once we control for human capital.

The alternative outcome concerns specialization: at any level of human capital, women pursue distinctive occupational careers (Jarman, Blackburn, and Racko, 2012; Shauman, 2006). For example, in Scandinavian countries, where many women have tertiary education, women follow feminized career ladders in the public sector (Hansen 1997; Mandel 2012). Likewise, highly qualified members of certain minorities tend to avoid the "ethnic penalty" (Heath, McMahon, and Roberts 2000) that they might endure in the broader labor market by carving out occupational niches in which they achieve a certain critical mass (Lieberson 1988) or serve a co-ethnic clientele (Aldrich, Cater, Jones, Evoy, and Velleman 1985). In Great Britain, Indian and Black African men have Medical practitioners and Software analysts among their most common occupations and, together with the Chinese, often work in professional and business services (Author1 and et.al. 2005; Clark and Drinkwater 2009; Modood and Berthoud 1997; Pang and Lau 1998).

The specialization story is likely most often referenced in the cases of workers in the lowest echelons of human capital formation. Women without tertiary education who join the labor market intermittently are often employed in female, "working class" occupations 
or in service occupations with flexible schedules (Cotter, Hermsen, and Vanneman 2004; Hakim 2004), while minorities with few qualifications concentrate in the least desirable occupations. For example, South Asian women in the North of England have traditionally worked as sewers in the textile and clothing industry (many at home) and South Asian men in taxi driving (Author1 and et.al. 2005; Clark and Drinkwater 2009; Green, Owen, and Wilson 2005; Modood and Berthoud 1997; Phizacklea and Wolkowitz 1995). In the US, Catanzarite (2000) has found that recent immigrant Latinos, who have a limited stock of human capital (Wright and Ellis 2000), concentrate in "brown-collar" occupations in the agriculture, construction, manufacturing, and low-level service sectors. In summary, the specialization argument posits that women and minorities with high and low levels of human capital concentrate heavily in subsets of occupations, thereby increasing the overall level of segregation. If this is the case, then we should observe that segregation increases once we control for human capital. Moreover, the findings should attest to the existence of a multiplicative interaction between ethnicity and gender.

To our knowledge, no contribution to the literature would lead us to expect any particular pattern in the way in which the dwindling interaction between ethnicity and gender, if any, might behave, once we account for the human capital characteristics of women and men and of each ethnic group. Under this scenario, such control will simply help us assess the robustness of the findings to the possible confounding effect of human capital.

To assess the sensitivity of our results to human capital characteristics, we exploit the information available in the Census related to educational achievement and age, which together can be considered proxies of education and potential work experience. First, we classify workers into occupations and $H$ human capital proxy categories. We denote by $M^{* *}$ the $M$ index of segregation by ethnicity and gender in terms of human capital and occupational categories. We can decompose $M^{* *}$ as follows:

$$
M^{* *}=M_{H C}+M_{o c c(H C)}
$$

where $M_{H C}$ is a between-term that captures the segregation induced by human capital levels and is of little interest for our purposes. $M_{o c c(H C)}$ averages the ethnic and gender segregation that exists for each level of human capital. In particular, 


$$
M_{o c c(H C)}=\sum_{h} p_{h} M(h) .
$$

Each of these terms $M(h)$ can itself be decomposed, as in equation (2), so that, for each human capital level, we can identify the interaction term using an expression such as equation (3). Hence, the decomposability properties of the $M$ index ensure that our notion of overall segregation and the identification of the interaction term can also be implemented after controlling for human capital categories.

\section{An Empirical Illustration}

We illustrate our approach using aggregated individual-level data from the 2001 Census of England and Wales. ${ }^{10}$ First we describe the data and the variables used. We then present and discuss our results.

\section{Data}

British society is one of the most diverse in Europe. Even so, people from the six major ethnic minorities in Britain (Indian, Black Caribbean, Pakistani, Black African, Chinese and Bangladeshi) represent only 5.5 percent of the working population. ${ }^{11}$ To contextualize the ethnic heterogeneity of the British labor force, recall that-according to the US Census Bureau - in 2000, 26.3 percent of workers in the US did not place themselves in the "white alone, not Hispanic or Latino" category. Given the scant demographic importance of minorities in Britain, Census data - with its almost universal coverage and fully coded occupational questions - constitute the only dataset that is sufficiently large and representative to analyze occupational segregation by ethnicity and gender.

\footnotetext{
${ }^{10}$ We created an aggregated data extract from the mainframe dataset with the 100 percent, individuallevel, Census data. The extract, which only includes the variables and the population subgroups we analyze, is held by the UK Office for National Statistics, to which applications for access should be directed.

${ }^{11}$ White includes people who define themselves as white British or Irish. We study them and the six minorities mentioned because they are the major and most stable sources of ethnic self-identification of people in Great Britain. Together, these seven ethnicities comprise 98 per cent of the British population (Clark and Drinkwater 2009). We do not consider people who declare themselves to belong to a mixed, or "Other," ethnic category because, in the aggregate, such forms of self-identity are subject to great variability over time (Simpson and Akinwale 2007).
} 
However, as noted above, minorities are unequally distributed throughout Britain (Clark and Drinkwater 2002). Local Authority Districts (LADs) are the lowest level of geographical information in our data. On average, each LAD has a population of around 140, 000 individuals (Clark and Drinkwater 2010). Casting a broad net, we define areas where five percent or more of the population declare themselves to be members of an ethnic minority as ethnically heterogeneous areas-"Mixed" for short. This figure rounds off the 5.5 percent of the ethnic minority people in the overall British labor force. Additionally, it divides the country neatly by grouping together all metropolitan areas in the Mixed group: from Portsmouth, with a 5 percent ethnic minority population, to Newham, a borough of East London where 60 percent of the population belongs to an ethnic minority. In total there are 113 Mixed LADs. ${ }^{12}$ Below the five percent benchmark, there are 408 LADs, which we call Non-mixed areas.

Tables 1 and 2 provide basic descriptive statistics of the dataset. Minority workers concentrate in Mixed areas: 86.5 percent of them, but only 37.6 percent of white workers, are found there. Women and men are similarly distributed, both across and within Mixed and Non-mixed areas. On average, 11.9 percent of workers in Mixed areas belong to a minority, in contrast to the 1.2 percent in Non-Mixed areas.

We use the 2000 Standard Occupational Classification, which has 81 categories at the three-digit level (ONS 2000). This is the most detailed classification available in British Census data when used in conjunction with variables such as ethnicity. Many researchers have noted that the more occupations existing in a classification, the higher the measure of segregation. Baron and Bielby (1980) have argued that the numerous jobs that official classifications subsume under the same occupational title are segregated by gender and, possibly, ethnicity. From this perspective, segregation indexes that use occupational-level information systematically under-report the degree of segregation (Reskin 1993).

Nonetheless, comparisons of segregation levels measured at different degrees of occupational detail report that most segregation is visible at a surprisingly high level of aggregation (Author2, Author3, and Other 2005; Charles and Grusky 2004). The rea-

\footnotetext{
${ }^{12}$ See Lupton and Power (2004) for the full list of LADs by percentage of ethnic minorities. See also Clark and Drinkwater (2002) for a discussion of the economic consequences of minority concentration in relatively deprived areas. These economists use the five percent figure as one of their basic benchmarks. Nonetheless, it is obvious that this number is not set in stone. Instead, it should be argued case by case, depending on the overall representativeness of the subpopulation of interest. For example, in her study of recent immigrant Latinos, Catanzarite (2003) uses a one percent criterion in her classification of metropolitan areas.
} 
Table 1: Ethnic Groups by Type of Area

England and Wales. Census Data. 2001

\begin{tabular}{lcccccc}
\hline \hline & \multicolumn{2}{c}{ Non-mixed areas } & \multicolumn{2}{c}{ Mixed areas } & \multicolumn{2}{c}{ Total } \\
& Counts & $\%$ & Counts & $\%$ & Counts & $\%$ \\
\hline White & $13,097,854$ & 98.8 & $7,878,540$ & 88.1 & $20,976,394$ & 94.5 \\
Indian & 59,562 & 0.4 & 407,449 & 4.6 & 467,011 & 2.1 \\
Black Caribbean & 25,237 & 0.2 & 222,308 & 2.5 & 247,545 & 1.1 \\
Pakistani & 21,004 & 0.2 & 158,078 & 1.8 & 179,082 & 0.8 \\
Black African & 16,129 & 0.1 & 158,073 & 1.8 & 174,202 & 0.8 \\
Chinese & 32,800 & 0.2 & 63,209 & 0.7 & 96,009 & 0.4 \\
Bangladeshi & 10,577 & 0.1 & 50,786 & 0.6 & 61,363 & 0.3 \\
Total & $13,263,163$ & 100 & $8,938,443$ & 100 & $22,201,606$ & 100 \\
\hline
\end{tabular}

Notes:

Only people aged 16 to 64 and in paid work are included.

Table 2: Joint Distribution of Ethnicity And Gender By Type of AreA England and Wales. Census Data. 2001

\begin{tabular}{lcccccc}
\hline \hline & \multicolumn{3}{c}{ Non-mixed areas } & \multicolumn{3}{c}{ Mixed Areas } \\
& Men & Women & Total & Men & Women & Total \\
\hline White People & 53.6 & 45.2 & 98.8 & 47.4 & 40.8 & 88.1 \\
Minorities & 0.7 & 0.5 & 1.2 & 6.5 & 5.3 & 11.9 \\
Total & 54.3 & 45.7 & 100 & 53.9 & 46.1 & 100 \\
Count & $7,200,521$ & $6,062,642$ & $13,263,163$ & $4,818,695$ & $4,119,748$ & $8,938,443$ \\
\hline
\end{tabular}

Notes:

Only people aged 16 to 64 and in paid work are included.

son is that a limited set of cleavages in the workplace determines much of the sorting of women and men across occupations: the manual divide, the cliff separating managerial and professional occupations from the rest, and the split into full-time and part-time jobs (Charles and Grusky 2004; Fagan and Rubery 1996), principally. For this reason, we deem the level of occupational aggregation that we employ acceptable for measuring segregation in the British labor market. If we had a more detailed classification, surely the levels of segregation we report would be higher, but we doubt that the patterns would change. Moreover, as Åslund and Skans (2009), Carrington and Troske (1997) and Winship (1977) note, analyzing extremely detailed units has the disadvantage of boosting the random variation that exists in the allocation of individuals across occupations.

We derive a proxy for human capital by combining six age groups (for ages 16 to 19, 
20 to 29,30 to 39,40 to 49, 50 to 59 and 60 to 64 ), and three levels of educational attainment (without academic or professional qualifications, with secondary or professional qualifications, and with tertiary qualifications). The resulting 18 categories tap into the different work experiences and educational attainments of women and men in each ethnic group (see Clark and Drinkwater 2009, for a similar operationalization of human capital). Ethnic minorities have a younger age structure and higher levels of educational qualifications (a point that Leslie, Drinkwater, and O'Leary 1998, and Clark and Drinkwater 2007, have noted already). For example, the percentage of people aged between 20 and 29 years is around 28 percent for minorities and only 19 percent for White people. A larger percentage of ethnic minorities under 40 have more tertiary education than do White peoples, with the only exceptions being Caribbean men and Bangladeshi people. In summary, White people have an older age profile and lower levels of education among the youngest age group. Hence, overall, the potential for having accrued work experience is greater among white workers than among minorities.

\section{Results and discussion}

In Table 3, we report, separately, the $M$ indexes based on the traditional notions of occupational segregation by ethnicity, $M^{e}$, and by gender, $M^{g}$. The value for ethnic segregation, 1.4, is very small. To appreciate this, the possible maximum value that ethnic segregation can reach is 194.6 (the natural logarithm of 7 times 100). In addition, of a maximum of 69.3 (the natural logarithm of 2 times 100), gender segregation stands at $20.1 .^{13}$

However, we cannot bluntly collate measures of gender segregation with measures of ethnic segregation because they are scaled differently. The standard practice is to normalize both. Most authors juxtapose normalized values of the $D I$ index ranging from 0 to 100 . In our case, we would conclude that gender induces $\frac{21.7}{69.3} x 100=29.05$ percent of the maximum it could reach, while ethnicity originates a meager $\frac{1.4}{194.6} x 100=0.71$ percent of its maximum. However, as discussed above, to directly compare the role of gender segregation and ethnic segregation, we must apply the $S G D$ property of the $M$ index shown in equation (2), to the partition of the population into 14 subgroups (2

\footnotetext{
${ }^{13}$ For clarity, we report the indexes multiplied by 100 and rounded to the first decimal point. Additionally, we report the results obtained with seven significant digits. For example, the value 20.1 for gender segregation found in Table 3 is the result of rounding $0.2013721 x 100$.
} 
Table 3: Measurements of Occupational Segregation

Mutual Information Indexes. England and Wales. Census Data. 2001.

\begin{tabular}{|c|c|c|c|c|c|}
\hline (1) & (2) & (3) & (4) & (5) & (6) \\
\hline 1.4 & 20.1 & 21.7 & 1.6 & 20.3 & -0.17 \\
\hline
\end{tabular}

(1) By Ethnic Group
(2) By Gender
(3) Jointly By Ethnic Group and Gender
(4) By Ethnic Group within Gender
(5) By Gender within Ethnic Group
(6) Putative Interaction between Ethnicity and Gender

genders times 7 ethnic groups). The relevant information is in column 3 of Table 3.

By definition, the segregation that ethnicity and gender jointly induced, measured by $M^{*}$, cannot be less than either ethnic or gender segregation measured separately, by $M^{e}$ or $M^{g}$, as equation (2) shows. $M^{*}$ stands at 21.7, while $M^{e}$ and $M^{g}$ are 1.4 and 20.1, respectively. However, in relative terms, this value of $M^{*}$ represents only $\frac{21.7}{264}=8.22$ percent of the maximum level of segregation that ethnicity and gender could generate together. The reason, of course, is that the low segregative effect of ethnicity compensates for the greater impact of gender and that the denominator is much larger than before: the logarithm of $2 x 7=14$ ethnic-gender groupings, which is approximately 1.146.

One advantage of this methodological framework is that we can provide a meaningful answer to the basic question: "How does ethnic segregation compare with gender segregation?" If there were no segregation by gender within ethnic groups, i.e., if $\sum_{e} p_{e} M^{g}(e)=0$, then overall segregation, $M^{*}$ in equation (2), would decrease by $\frac{20.3}{21.7} x 100=93.6$ percent. In contrast, if there were no ethnic segregation within genders, i.e., if $\sum_{g} p_{g} M^{e}(g)=0$, then $M^{*}$ would only decrease by $\frac{1.6}{21.7} x 100=7.2$ percent. Though these numbers merely confirm the well-known fact that the segregative force of gender overpowers that of ethnicity, it is worth appreciating that the $M$ index allows us to demonstrate that fact in such a parsimonious and rigorous manner. Traditionally, researchers would produce dichotomous indexes for pairs of comparisons ranging from the simplest instance, in which 
there are only 2 ethnicities and 2 genders, to the 52 ethnic-race-gender groupings studied by Reskin and Cassirer (1996). In the first case, there is a manageable set of $\left(\begin{array}{l}4 \\ 2\end{array}\right)=6$ pairs. However, in the second situation, the output, $\left(\begin{array}{c}52 \\ 2\end{array}\right)=1,326$ pairs, is so unwieldy that analysts face "a complexity that does not lend itself to easy summarization" (ibid.: 234).

For comparative purposes, we could calculate $\left(\begin{array}{c}14 \\ 2\end{array}\right)=91$ local $M$ indexes, one for each pair of our 14 ethnic-gender groupings. Nevertheless, sensu stricto, we cannot set side-byside pairwise indexes of, say, gender segregation in a given ethnic group with the indexes of ethnic segregation for each gender because they do not lie along a common scale of ethnic and gender segregation. Moreover, using traditional indexes in our comparison would be very limited because, under the latter approach, local indexes - of ethnic segregation for each gender and of gender segregation for each ethnicity - cannot be added together, nor can the exclusive contribution of each variable to segregation be isolated. As explained above in the presentation of the $M$ index, these two latter measurements are the auxiliary terms needed to identify interactions between ethnicity and gender, as well as their additive effects on segregation. This question is at the core of our inquiry. We turn our attention to it in the next subsection.

\section{How do gender and ethnicity interact?}

To determine how ethnicity and gender combine as sources of occupational segregation, we can compute intersection $I$ using equation (3), i.e., we subtract from $M^{*}$ the net inputs of each variable. The result is -0.17 (column 6 in Table 3). ${ }^{14}$ Therefore, we conclude that the action of one dimension somehow diminishes the segregative potential of the other. Thus, the joint effect of ethnicity and gender on segregation produces a dwindling interaction between the two dimensions. Reskin's and Cassirer's (1996) intuition is borne out by our identification strategy.

Still, we must recognize that the interaction is small. It represents a scant $\frac{0.17}{21.7} x 100=$ 0.78 percent of the segregation that ethnicity and gender together produce. We can examine the issue from two perspectives. First, let us focus on ethnic segregation once we control for gender (column 4 in Table 3). In this case, the index is 1.6. When we do not exert this control and simply measure ethnic segregation in terms of $M^{e}$, the figure

\footnotetext{
${ }^{14}$ Again, we report the rounded results of calculations with seven significant digits. Hence, we calculate $[0.2168989-(0.0155268+0.2030584)] x 100=-0.17$
} 
is similar, though slightly lower: 1.4 (column 1 in Table 3). In other words, the added information that we gain by knowing someone's gender does not significantly alter the occupational distribution predicted on the basis of ethnicity.

Second, let us turn to gender. Because interactions are commutative and because we already know that ethnic segregation does not vary once we control for gender, after controlling for ethnicity, gender segregation should remain roughly equal to what it was on its own. The comparison between columns 5 and 2 of Table 3 confirms this presumption. The level of gender segregation increases somewhat, from its value of $M^{g}=20.1$ to 20.3 when we control for ethnicity. In brief, conditioning on ethnicity hardly influences the distribution of women and men across occupations. Gender induces more occupational segregation than ethnicity does, and each factor reduces, very slightly, the impact of the other on segregation. Altogether, however, each ascribed characteristic segregates workers independently of the segregation induced, simultaneously, by the other dimension.

This conclusion may surprise theorists of intersectionality. ${ }^{15}$ Therefore, it is fair to ask whether it is also surprising in the context of the literature on ethnic and gender occupational segregation in Great Britain. This corpus is small and recent because official statistics have included data on ethnicity only since the 1980s. In particular, three studies have posed the question of whether ethnicity interacts with gender multiplicatively, such that the two statuses reinforce each other in creating segregation for ethnic minority women. To address this multiplicative conjecture, the three studies have relied on contingency tables showing the occupational distributions of women and men of various ethnic groups. However, the authors differ in the number of ethnicities considered, the data used, and the degree of detail employed in their occupational classifications. King (1995) analyzes the 1989 Labour Force Survey (LFS), the British equivalent of the US Current Population Survey, and concentrates on the contrast between the White and Black categories. In contrast, Abbott and Tyler (1995) and Blackwell (2003) draw on the 1991 Census data, which was the first Census to ask for ethnic information. Moreover, Abbott, Tyler and Blackwell include in their tables all of the ethnic groups that we use in this article.

These researchers draw very different conclusions. King argues for the intersection of

\footnotetext{
${ }^{15}$ Nevertheless, we should recall that our measurements are rooted in quantitative, hypothesis-testing research. Consequently, we do not and cannot say anything about the painful, subjective experiences that ensue from the double burden of racism and sexism that minority women experience in their everyday lives (Browne and Misra 2003; McCall 2005).
} 
ethnicity and gender in the manner to which we alluded in the literature review section: "Black women are even more concentrated in 'women's jobs' than are white women" (1995, 26). Abbott and Tyler, conversely, cannot "confirm any tendency for non-white women to be segregated uniformly in the 'lower' employment grades" (Abbott and Tyler 1995, 339). For her part, Blackwell finds that Other Asian, Black African, and Chinese people are more likely to be in the most advantageous occupations than White people. On these grounds, she concludes that "ethnicity and gender do not combine to create double disadvantage for minority women in the labor market" (Blackwell 2003, 713).

Surely, to a certain extent, these disparate conclusions are due to the different data used and to the relatively small sample size of the LFS in comparison to the Census. Arguably, another reason for the discrepancy lies in King's merging of the Black African and Black Caribbean categories into a single "Black" group. As Blackwell notes, Black people of African origins are more successful in terms of occupational attainment than Black people from the Caribbean. Nevertheless, none of these authors employ a systematic method of identifying the joint effect of ethnicity and gender. They rely on contingency tables of workers' distribution across major occupational titles by ethnicity and gender. In addition, Blackwell (2003) and Author1 and et.al. (2005) make pairwise comparisons using the Gini index. In contrast, the method that we propose offers a single metric by which we can conclude, unambiguously, that the dependence between ethnic and gender segregation is minimal.

\section{Sensitivity of the results to compositional effects}

The $M$ index is not "margin free": it is sensitive to the shares of each ethnic-gender group in the population and to the overall occupational mix. Intuitively, if the proportion of minority workers varied, our initial uncertainty about a worker's ethnicity would change. Furthermore, after learning her or his occupation, our ethnic uncertainty would also adjust to the new proportion. As Frankel and Volij (2011) state, this fact makes the index "unsuitable for judging whether different (...) groups are becoming more similarly distributed" across different organizational units over time.

Our research covers one year only. Nevertheless, the violation of the margin free property could entail that our conclusions regarding intersectionality are driven by the ethnic composition of the population. Is the observed, but tiny, dwindling effect an 
outcome of the small proportion of minorities in Britain? We explore the consequences for our results of measuring ethnic and gender segregation in Mixed areas, where the average percentage of minority workers (11.9) is almost ten times larger than the average percentage in Non-mixed areas (1.2). Perhaps unsurprisingly, according to the $M *$ index, there is more ethnic segregation and a stronger interaction between ethnicity and gender in areas of the country with sizable ethnic minorities. However, though 88.1 percent of the working population in the Mixed areas is white, overall segregation would decrease by a non-negligible $\frac{2.8}{20.8}=13.5$ percent if ethnicity played no role in the segregative process (see columns 3 and 4 of Panel 1, Table 4). Moreover, in column 4 of Table 4, Panel 1, the net contribution of ethnicity is $\frac{2.8}{0.7} x 100=4.1$ times larger than in Non-Mixed areas; and, finally, in the column 6 , the magnitude of the dwindling interaction is $\frac{0.28}{0.05}=5.9$ times larger.

We conclude that a) the ethnic composition of Local Authority Areas influences our measurements to some extent but that b) it does not alter the main finding: ethnicity and gender interact slightly in a dwindling way; on the whole, they bring about segregative processes that are independent of each other.

The second robustness check involves controlling for a proxy of human capital. Earlier in the article, we discussed the literature and summarized its expectations in the form of two arguments. One vision posits that workers are not segregated on account of their ethnicity and gender but because they have different degrees of work experience due to their age and educational qualifications. Leaving aside the possibility of age discrimination and the fact that investment in education, to a large extent, reflects class differences (Breen and Jonsson 2005), this picture comes close to the meritocratic ideal: an occupation for everyone in accordance with one's own merits. If this interpretation is correct, then ethnic and gender segregation should disappear or, at least, shrink drastically once differences in age and educational attainment are controlled for. Moreover, under these circumstances, there should be no interaction whatsoever between ethnicity and gender.

Alternatively, each ethnic-cum-gender population subgroup may specialize occupationally at any given level of human capital: members of each of these subgroups with minimal qualifications concentrate in a set of low-level, low-paying occupations with little prestige, while the members who obtain educational credentials concentrate in certain occupations at the top end of the classification. In any case, the outcome in terms of segregation would be that there is a multiplicative interaction between ethnicity and 
Table 4: Measurements of Segregation by Human Capital and Area Mutual Information Indexes. England and Wales. Census Data. 2001.

Panel 1: Without controlling for human capital

$\begin{array}{lllll}(1) & (2) \quad(3) & (4) & (5) & (6)\end{array}$

$\begin{array}{lllllll}\text { Non-mixed areas } & 0.6 & 21.7 & 22.4 & 0.7 & 21.7 & -0.05\end{array}$

$\begin{array}{lllllll}\text { Mixed areas } & 2.5 & 18.0 & 20.8 & 2.8 & 18.3 & -0.28\end{array}$

Panel 2: Controlling for human capital

$\begin{array}{llllll}(1) & (2) & (3) & (4) & (5) & (6)\end{array}$

\begin{tabular}{lllllll} 
Non-mixed areas & 0.7 & 22.8 & 23.5 & 0.7 & 22.8 & -0.07 \\
Mixed areas & 3.2 & 19.1 & 22.6 & 3.5 & 19.3 & -0.28 \\
\hline
\end{tabular}

\section{Notes:}

(1) By Ethnic Group

(2) By Gender

(3) Jointly By Ethnic Group and Gender

(4) By Ethnic Group within Gender

(5) By Gender within Ethnic Group

(6) Putative Interaction between Ethnicity and Gender

Only people aged 16 to 64 and in paid work are included. 
gender - the women and men of each ethnic group are located in different occupational niches - and such interaction, together with overall segregation, rises once we compare people of like age and education.

What is the verdict? When we control for human capital, ethnic and gender segregation increases somewhat by $\frac{23.5-22.4}{23.5} x 100=4.7$ percent in Non-mixed areas and by $\frac{22.6-20.8}{22.6} x 100=8.0$ percent in Mixed areas (column 3 in Table 4). These results bear out the specialization interpretation to a certain degree: women and minorities follow relatively differentiated occupational careers at each level of human capital, and our measurement is sensitive to the compositional effect that is unveiled once we compare people of similar age and educational level with each other rather than with the whole population. This finding echoes the well-known fact that in spite of the trend towards gender equalization in education starting in the 1960s (Jacobs 1989), segregation persists over time at remarkably stable levels. It is reasonable to expect that better proxies for work experience and education (such as actual years employed and field of study; see Charles and Bradley 2002; England 2010; Shauman 2006) will accentuate the effects of occupational specialization among women and minorities. ${ }^{16}$

However, the interaction remains "dwindling" rather than multiplicative, and the change is minimal (column 6 of Table 4). Hence, our major conclusion with regard to the joint effect of ethnicity and gender is robust to this sensitivity check: even given the occupational specialization that controlling for human capital reveals, each ascribed characteristic slightly lessens the impact of the other characteristic on segregation. On the whole each status prompts independent segregative processes.

\section{Conclusions}

Fifteen years ago, Leffler and Xu (1996) wrote that "although everyone can be characterized in terms of both a sex and a race, relatively little research explores the effects of the two factors simultaneously on people's work fates." Likewise, Reskin and co-authors have called for further research on "the joint effects of race and 'sex' and for 'race' to be defined beyond the Black/white dichotomy" (Reskin, McBrier, and Kmec 1999). In light

\footnotetext{
${ }^{16}$ Moreover, as we noted above, the place where people were educated is a factor that may influence occupational outcomes (Heath and Yu 2005; Platt 2005). Unfortunately, Census data have limited information on fields of study and none at all on the countries where people obtained their education.
} 
of the increasing ethnic diversity of Western labor markets and their enduring gender inequalities, any sociologist would agree with such a research agenda. What stopped us then?

In the matter of occupational segregation, it turns out that the limits lay in the comforts of our old methodological tool: the $D I$ index. There is no doubt that this index has contributed much to social research since its introduction in 1955. However, it is striking that fifty years later, when quantitative articles routinely employ far more sophisticated models than in the 1950s, most segregation research still relies on a dichotomous measure that restricts comparisons to men vs. women, white vs. Black, and white vs. Nonwhite, among others. However, ethnic and gender categories are not mutually exclusive. People belong to one gender and to one ethnic group at the same time. Moreover, in any given setting, there are typically more than two ethnic groups. In fact, there are seven in our data.

The first contribution of this article has been to tailor the $M$ index to address Leffer's, Reskin's, Xu's and many others' calls for the joint study of ethnicity and gender in relation to occupational segregation. We exploit the fact that the $M$ index can be applied to analyze any partition of the population into as many groups as dictated by the researcher's goals (which, in our case, are $2 x 7=14$ ethnic-cum-gender categories). Updating the sociologists' toolkit in this manner, we have compared, rigorously, the relative importance of ethnicity and gender to occupational segregation. We have substantiated the claim that most ethnic and gender segregation would disappear if the share of women and men in each occupation were equal to their proportion in the overall working population. Nevertheless, ethnicity contributes up to 13.5 per cent of all segregation in Mixed areas, where minorities concentrate. In settings where ethnic groups have similar demographic weights, and/or where the segregative force of ethnicity is heightened (through, for example, exacerbated discrimination, an upsurge of occupational specialization among minorities, or blunt racial apartheid), the gap in the relative importance of ethnicity and gender may narrow.

However, the main purpose of a methodological framework that isolates the exclusive contribution of each status to segregation, net of any effects due to the other dimension, lies elsewhere; namely, in the identification of how the two statuses interact. We have found that there is a small "dwindling" interactive effect: ethnicity weakens the segregative power of gender, and vice versa. But the curtailment is minimal. By and large, the 
effects of ethnicity and gender on segregation are independent of each other. Minority women suffer segregation on account of both their ethnicity and their gender, but the consequences of belonging to both statuses overlap almost not at all. In King's terms (1988), altogether there is double, but not multiple, jeopardy in being an ethnic minority woman. Such an identification strategy relies on M's Strong Group Decomposability property.

Finally, we have conducted two robustness analyses. First, by splitting the population into two areas defined by proportions of ethnic minorities, we have assessed to what extent our main result is driven by the low presence of minorities in Britain. Second, we have explored the sensitivity of our results to controlling for age and educational levels. In the first place, unsurprisingly, we have corroborated that, as measured by the $M$ index, there is more ethnic segregation in ethnically mixed areas than in ethnically homogeneous ones. In the second place, our results support the specialization rendering of the human capital theory to a certain extent: women, men and ethnic groups are slightly more segregated from people of like educational levels and work experience than from the overall working population because each subgroup specializes occupationally. However, although each of these two compositional effects adds richness to the segregation story, they do not alter our fundamental finding: the dwindling, but tiny, interaction between ethnicity and gender.

\section{References}

Åslund, O., And O. N. SkAns (2009): "How to measure segregation conditional on the distribution of covariates," Journal of Population Economics, 22, 971-981.

(2010): "Will I see you at work? Ethnic workplace segregation in Sweden, 1985-2002," Industrial and labor relations review, 63(3), pp. 471-493.

Abbott, P., And M. Tyler (1995): "Ethnic Variation in the Female Labour Force: A Research Note," The British Journal of Sociology, 46(2), pp. 339-353.

AlbeldA, R. P. (1986): "Occupational segregation by race and gender, 1958-1981," Industrial and Labor Relations Review, 39, 404-411. 
Aldrich, H., J. Cater, T. Jones, D. M. Evoy, and P. Velleman (1985): "Ethnic Residential Concentration and the Protected Market Hypothesis," Social Forces, 63(4), pp. 996-1009.

Allen, J., And D. MAssey (eds.) (1988): The economy in question. Oxford University Press, Oxford.

Alonso-Villar, O., C. Del Rio, and C. Gradin (2012): "The extent of occupational segregation in the United States: Differences by race, ethnicity, and gender," Industrial relations: a journal of economy and society, 51(2), 179-212.

Author1, And Et.AL. (2005): “Anonymous," .

Author2, And Author3 (2011): "Anonymous," .

Author2, Author3, And Other (2005): "An algorithm to reduce the occupational space in gender segregation studies," Journal of Applied Econometrics, 20(1), 25-37.

BARon, J. N., And W. T. BielBy (1980): "Bringing the firms back in: stratification, segmentation, and the organization of work," American Sociological Review, 45(5), pp. $737-765$.

Batnitzky, A., And L. MCDowell (2011): "Migration, nursing, institutional discrimination and emotional/affective labour: ethnicity and labour stratification in the UK National Health Service," Social \& Cultural Geography, 12(2), 181-201.

BeAL, F. M. (1969): "Double Jeopardy: To Be Black and Female," Hartford Web Publishing. http://www.hartford-hwp.com/archives/45a/196.html. (Date of retrieval: 6 August 2012).

BECKeR, G. S. (1971): The Economics of discrimination. The University of Chicago Press, Chicago.

Becker, H. S. (1963): Outsiders: Studies in the Sociology of Deviance. The Free Press, New York.

Ben-Porath, Y. (1967): "The Production of Human Capital and the Life Cycle of Earnings," Journal of Political Economy, 75(4), pp. 352-365. 
Berthoud, R. (2000): "Ethnic employment penalties in Britain," Journal of Ethnic and Migration Studies, 26(3), 389-416.

Bertrand, M., D. Chugh, and S. Mullainathan (2005): "Implicit Discrimination," The American Economic Review, 95(2), pp. 94-98.

BLACKWELL, L. (2003): "Gender and ethnicity at work: occupational segregation and disadvantage in the 1991 British Census," Sociology, 37(4), 713-731.

Blau, F. D., M. C. Brinton, And D. B. Grusky (eds.) (2006): The Declining Significance of Gender? Russell Sage Foundation, New York.

Bradley, H., And G. Healy (2008): Ethnicity and Gender at Work. Inequalities, Careers and Employment Relations. Palgrave Macmillan.

Breen, R., And J. O. Jonsson (2005): "Inequality of Opportunity in Comparative Perspective: Recent Research on Educational Attainment and Social Mobility," Annual Review of Sociology, 31(1), 223-243.

Browne, I., AND J. MisRa (2003): "The intersection of gender and race in the labor market," Annual Review of Sociology, 29(1), 487-513.

Carmichael, F., and R. Woods (2000): "Ethnic Penalties in Unemployment and Occupational Attainment: Evidence for Britain," International Review of Applied Economics, 14(1), 71-98.

Carrington, W. J., and K. R. Troske (1997): "On Measuring Segregation in Samples with Small Units," Journal of Business 8 Economic Statistics, 15(4), pp. 402-409.

Castilla, E. J. (2008): "Gender, race, and meritocracy in organizational careers," American journal of sociology, 113(6), pp. 1479-1526.

Catanzarite, L. (2000): "Brown-Collar Jobs: Occupational Segregation and Earnings of Recent-Immigrant Latinos," Sociological Perspectives, 43(1), pp. 45-75.

- (2003): "Occupational context and wage competition of new immigrant latinos with minorities and whites," The Review of Black Political Economy, 31(1-2), 77-94. 
Charles, M., and K. Bradley (2002): "Equal but Separate? A Cross-National Study of Sex Segregation in Higher Education," American Sociological Review, 67(4), pp. $573-599$.

Charles, M., And D. Grusky (2004): Occupational ghettos: The worldwide segregation of women and men. Stanford Univ Press.

Chugh, D. (2004): "Societal and Managerial Implications of Implicit Social Cognition: Why Milliseconds Matter," Social Justice Research, 17, 203-222.

Clark, K., And S. Drinkwater (2002): "Enclaves, neighbourhood effects and employment outcomes: Ethnic minorities in England and Wales," Journal of Population Economics, 15(1), 5-29.

Clark, K., and S. Drinkwater (2007): Ethnic minorities in the labour market. Dynamics and diversity. The Policy Press.

(2009): "Immigrant self-employment adjustment: Ethnic groups in the UK," International Journal of Manpower, 30(1/2), 163-175.

(2010): "Patterns of ethnic self-employment in time and space: evidence from British Census microdata," Small business economics, 34(3), 323-338.

Cohn, S. (1999): Race, Gender, And Discrimination At Work. Westview Press.

Collins, R. (2000): "Social stratification: A micro-macro theory of inequality," Sociological Theory, 18(1), 17-43.

Cotter, D. A., J. M. Hermsen, and R. Vanneman (2004): "Gender inequality at work," Discussion paper, Russell Sage Foundation and Population Reference Bureau.

Cross, M. (ed.) (1992): Ethnic minorities and industrial change in Europe and North America. Cambridge University Press, Cambridge.

Crouch, C. (1999): Social change in Western Europe. Oxford University Press, Oxford.

Durlauf, S. N. (2004): "Neighborhood effects," in Handbook of Regional and Urban Economics, ed. by J. V. Henderson, and J.-F. Thisse, vol. 4 of Handbook of Regional and Urban Economics, chap. 50, pp. 2173-2242. Elsevier. 
England, P. (2010): "The Gender Revolution," Gender \& Society, 24(2), 149 -166.

Epstein, C. F. (1973): "Positive Effects of the Multiple Negative: Explaining the Success of Black Professional Women," American Journal of Sociology, 78(4), pp. 912-935.

L (2007): "Great Divides: The Cultural, Cognitive, and Social Bases of the Global Subordination of Women," American Sociological Review, 72(1), 1-22.

FAGAn, C., And J. Rubery (1996): "The salience of the part-time divide in the European Union," European Sociological Review, 12(3), 227-250.

Fernández, R. (2010): "Does Culture Matter?," Working Paper 16277, National Bureau of Economic Research.

FlüCKIGER, Y., AND J. Silber (1999): The Measurement of Segregation in the Labor Force. Physica-Verlag HD.

Frankel, D. M., AND O. VOLIJ (2011): "Measuring school segregation," Journal of Economic Theory, 146(1), 1-38.

Green, A., D. Owen, And R. A. Wilson (2005): "Changing patterns of employment by ethnic group and for migrant workers," Discussion paper, Warwick.

HAKIM, C. (2004): Key Issues in Women's Work: Female Diversity and the Polarisation of Women's Employment. The GlassHouse Press.

Hamming, R. W. (1991): The art of probability for scientists and engineers. AddisonWesley Publishing Company.

Hansen, M. N. (1997): "The Scandinavian Welfare State Model: The Impact of the Public Sector on Segregation and Gender Equality," Work, Employment 8 Society, 11(1), 83-99.

Heath, A., D. McMahon, and J. Roberts (2000): "Ethnic differences in the labour market: a comparison of the samples of anonymized records and Labour Force Survey," Journal of the Royal Statistical Society: Series A (Statistics in Society), 163(3), 303339. 
Heath, A., And S. Yu (2005): "Explaining ethnic minority disadvantage," in Understanding social change, ed. by A. Heath, J. Ermisch, and D. Gallie, pp. 187-224. Oxford University Press, Oxford.

Hegewisch, A., H. Liepmann, J. Hayes, and H. Hartmann (2010): "Separate and Not Equal? Gender Segregation in the Labor Market and the Gender Wage Gap," Discussion paper, Institute for Women's Policy Research, http://www.iwpr.org.

Hughes, E. C. (1945): "Dilemmas and contradictions of status," The American Journal of Sociology, 50(5), 353-359.

JACOBS, J. A. (1989): "Long-term trends in occupational segregation by sex," American Journal of Sociology, 95(1), 160-173.

JaCOBS, J. A., And M. BlaiR-Loy (1996): "Gender, race, local labor markets, and occupational devaluation," Sociological Focus, 29(3), 209-230.

Jarman, J., R. M. Blackburn, and G. Racko (2012): "The Dimensions of Occupational Gender Segregation in Industrial Countries," Sociology, 46(6), 1003-1019.

Kaufman, R. L. (2010): Race, gender, and the labor market: Inequalities at work. Lynne Rienner Publishers, Boulder, CO.

King, D. K. (1988): "Multiple Jeopardy, Multiple Consciousness: The Context of a Black Feminist Ideology," Signs, 14, 42-73.

KING, M. (1995): "Black women's labor market status: Occupational segregation in the United States and Great Britain," The Review of Black Political Economy, 24(1), $23-43$.

KInG, M. C. (2009): "Occupational Segregation by Race and Sex in Brazil, 1989-2001," The review of black political economy, 36, 113-125.

LEFFler, A., AND W. XU (1996): "Gender and race impacts on occupational segregation, prestige and earnings," in Women and work. A handbook, ed. by P. J. Dudeck, and K. Borman. Garland Publishing, Inc., New York. 
Leslie, D., S. Drinkwater, and N. O'Leary (1998): "Unemployment and earnins among Britain's ethnic minorities: some signs for optimism," Ethnic and Racial Studies, $25,489-506$.

Lieberson, S. (1988): A Piece of the Pie: Blacks and White Immigrants Since 1880. University of California Press.

Lieberson, S., And M. C. Waters (1988): From many strands. Ethnic and racial groups in contemporary America. Russell Sage Foundation, New York.

Lupton, R., And A. Power (2004): "Minority ethnic groups in Britain," CASEBrookings Census Briefs, 2.

MAndel, H. (2012): "Winners and Losers: The Consequences of Welfare State Policies for Gender Wage Inequality," European Sociological Review, 28(2), 241-241.

Massey, D. S., And N. A. Denton (1988): "The Dimensions of Residential Segregation," Social Forces, 67(2), pp. 281-315.

MCCALL, L. (2001): Complex inequality: Gender, class and race in the new economy. Routledge, New York.

MCCALL, L. (2005): "The Complexity of Intersectionality," Signs, 30(3), 1171-1800.

Mintz, B., And D. H. KRYMkowski (2011): "The intersection of race/ethnicity and gender in occupational segregation. Changes over time in the contemporary United States," International Journal of Sociology, 40(4), 31-58.

MisRA, J. (2012): "Introduction," Gender $\&$ Society, 26(1), 5-13.

Modood, T., And R. Berthoud (1997): Ethnic minorities in Britain. Policy Studies Institute, London.

Moss, P., And C. Tilly (2001): Stories employers tell: Race, skill, and hiring in America. Russell Sage Foundation, New York.

Nakano Glenn, E. (1985): "Racial Ethnic Women's Labor: The Intersection of Race, Gender and Class Oppression," Review of Radical Political Economics, 17(3), 86-108. 
ONS (2000): "Standard Occupational Classification 2000. Volume 1: Structure and Definition of the Unit Groups," .

Owen, D., And A. Green (1992): "Labour market experience and occupational change amongst ethnic groups in Great Britain," Journal of Ethnic and Migration Studies, 19(1), 7-29.

PANG, M., And A. LAU (1998): "The Chinese in Britain: working towards success?," The International Journal of Human Resource Management, 9(5), 862-874.

PARKER, S. C. (2004): The economics of self-employment and entrepreneurship. Cambridge University Press, Cambridge.

Phelps, E. S. (1972): "The Statistical Theory of Racism and Sexism," The American Economic Review, 62(4), pp. 659-661.

Phizacklea, A., and C. Wolkowitz (1995): Homeworking Women: Gender, Racism and Class at Work. Sage Publications Ltd, London.

Platt, L. (2005): Migration and social mobility. The life chances of Britain's minority ethnic communities. The Policy Press, Bristol.

Puyenbroeck, T. V., K. D. Bruyne, and L. Sels (2012): "More than 'Mutual Information': Educational and sectoral gender segregation and their interaction on the Flemish labor market," Labour Economics, 19(1), 1 - 8 .

Reardon, S. F., And G. Firebaugh (2002): "Measures of Multigroup Segregation," Sociological Methodology, 32, pp. 33-67.

Reskin, B. (1993): "Sex segregation in the workplace," Annual Review of Sociology, 19, $241-270$.

Reskin, B., And N. CASsirer (1996): "Occupational segregation by gender, race and ethnicity," Sociological Focus, 29(3), 231-243.

Reskin, B. F., D. B. McBrier, And J. A. Kmec (1999): "The determinants and consequences of workplace sex and race composition," Annual Review of Sociology, 25(1), 335-361. 
Reskin, B. F., And I. PAdaviC (1999): "Sex, race, and ethnic inequality in United States workplaces," in Handbook of the Sociology of Gender, ed. by J. S. Chafetz. Kluwer Academic/Plenum Publishers, New York.

Reskin, B. F., And P. A. Roos (1990): Job Queues, Gender Queues. Explaining Women's Inroads into Male Occupations. Temple University Press.

RIDGEWAY, C. L. (2006): "Gender as an organizing force in social relations: Implications for the future of inequality," in The declining significance of gender?, ed. by F. D. Blau, M. C. Brinton, and D. B. Grusky. Russell Sage Foundation.

Shauman, K. A. (2006): "Occupational sex segregation and the earnings of occupations: What causes the link among college-educated workers?," Social Science Research, 35(3), $577-619$.

Simpson, L., and B. Akinwale (2007): "Quantifying stability and change in ethnic group," Journal of Official Statistics, 23(2), 185.

TiEndA, M., AND D.-T. LiI (1987): "Minority concentration and earnings inequality: Blacks, Hispanics, and Asians compared," American Journal of Sociology, 93(1), 141165.

Tomaskovic-Devey, D. (1993): Gender and Racial Inequality at Work: The Sources and Consequences of Job Segregation. ILR Press, Ithaca, New York.

Waldinger, R., And C. Feliciano (2004): "Will the new second generation experience 'downward assimilation'? Segmented assimilation re-assessed," Ethnic and Racial Studies, 27(3), 376-402.

West, C., and D. Zimmerman (1987): "Doing gender," Gender \& society, 1(2), 125151.

Winship, C. (1977): "A Revaluation of Indexes of Residential Segregation," Social Forces, 55(4), pp. 1058-1066.

Wright, R., And M. Ellis (2000): "The Ethnic and Gender Division of Labor Compared Among Immigrants to Los Angeles," International Journal of Urban and Regional Research, 24(3), 583-600. 
Xu, W., AND A. LefFler (1992): "Gender and race effects on occupational prestige, segregation, and earnings," Gender \& Society, 6(3), 376-392. 